\title{
Non-viral Microbial Keratitis in a Tertiary Care Hospital in Bangladesh
}

\author{
Mohammed Selim Reza*1, Shamsul Alam Chowdhury², Paritush Kanti Talukder ${ }^{3}$, \\ Md. Tabibul Islam ${ }^{4}$, Md. Altaf Hossain, Nizam Jamil Hussain ${ }^{6}$, Azima Aktar Jhuma7
}

\begin{abstract}
:
Introduction: Microbial keratitis is a serious ocular infectious disease that can lead to significant visual loss and ophthalmic morbidity. Objectives were to see the profile of non-viral microbial keratitis in a tertiary care hospital in Bangladesh. Materials and Methods: This cross-sectional study was conducted in the Department of Ophthalmology, Sylhet MAG Osmani Medical College Hospital, Sylhet between January 2015 and December 2016. Results: The mean age of the patients was $46.7 \pm 16.5$ years with male preponderance $(54.4 \%)$. The most common predisposing factors were trauma $(66.7 \%)$, and chronic dacryocystitis (25.6\%). Fungal growth was more frequent compared to bacterial growth $70(77.7 \%)$ versus $30(33.3 \%)$, p<0.01). Gram positive organisms were Staphylococcus epidermidis $(11.1 \%)$, Staphylococcus aureus (3.3\%); gram negative organisms were Pseudomonas aeruginosa (12.2\%), Klebsiella species (3.3\%) and Escherichia coli (3.3\%). Aspergillus species (71.4\%) was the commonest fungus. Others were Penicillium species (7.1\%), Fusarium species (8.6\%), Mucor (10.0\%) and Rhizopus (2.9\%). Conclusion: Fungi are more frequent cause of non-viral keratitis. Watering, redness, pain or burning sensation, corneal opacity and dimness of vision are clinical profiles of non-viral microbial keratitis.
\end{abstract}

Key words: Microbial keratitis, Predisposing factors, Clinical profile.

Number of Tables: 04; Number of References: 27; Number of Correspondences: 06.

*1. Corresponding Author: Dr. Mohammed Selim Reza

Assistant Professor

Department of Ophthalmology

North-East Medical College, Sylhet.

Email: drselimreza44@gmail.com

2. Prof. Dr. Shamsul Alam Chowdhury

Professor and Head

Department of Ophthalmology

North-East Medical College, Sylhet.

3. Dr. Paritush Kanti Talukder

Assistant Professor

Department of Ophthalmology

Sylhet MAG Osmani Medical College, Sylhet.

4. Dr. Md. Tabibul Islam

Assistant Professor

Department of Dermatology and Venereology

Sylhet MAG Osmani Medical College, Sylhet.

5. Dr. Md. Altaf Hossain

Assistant Professor

Department of Ophthalmology

Sylhet Women's Medical College, Sylhet.

6. Dr. Nizam Jamil Hussain

Consultant

Friends Eye Hospital, Akhalia, Sylhet.

7. Dr Azima Aktar Jhuma

Assistant Professor

Department of Microbiology

Sylhet MAG Osmani Medical College, Sylhet.

\section{Introduction:}

Keratitis is a vision threatening disease. The special importance of disease of the cornea lies in the fact that a corneal scar is the final outcome of any inflammation. Unlike healthy transparent corneal tissue, scar tissue is white and opaque in varying degrees of severity. They often leave permanent opacities which substantially diminish visual acuity, while the associated complications which not infrequently follow them may even lead to complete loss of vision ${ }^{1}$. Surveys in Asian countries (India, Bangladesh, Pakistan) for blindness and visual impairment also listed corneal scarring second only to cataract as the major etiology of blindness and visual disability ${ }^{2-4}$. In Bangladesh, $33.55 \%$ of all cases of unilateral blindness were reported due to complication of corneal ulcer ${ }^{5}$. Considering the predisposing factor of ocular trauma was predominant in all type of microbial keratitis. Other predisposing factors were ocular diseases, ocular surgery contact lens ${ }^{6}$. A wide spectrum of microbial organisms can produce corneal infection. The severity of corneal infection depends on the underlying condition of the cornea and pathogenecity of the infecting organism, and consequently the therapeutic strategies may be variable. Many differences in keratitis profile have been noted between populations living in rural or in urban areas in Western, or in developing countries. Gram positive bacterial species are more frequently recovered in temperate zones and gram-negative species are found in tropic climates ${ }^{7}$. Fungi reside as commensals in flora of the conjunctival sac in $3-28 \%$ of healthy eyes. Thus in the tropical countries, humid atmosphere and outdoor occupations make the population more vulnerable to fungal infections ${ }^{8}$. Besides, the bacteriological profile and their susceptibility as well as resistant patterns vary from place to place and in the same place from time to time ${ }^{9}$. Untreated, infective keratitis may lead 
to opacification and perforation of the cornea. The associated morbidity is the result of several factors and is directly affected by difficulties in patient's management because of a lack of diagnostic facilities and appropriate treatment. Specific treatment requires prompt and accurate identification of causative micro-organisms ${ }^{10}$. This study is conducted to identify the spectrum of non-viral microbial infectious keratitis in Sylhet MAG Osmani Medical College Hospital, Sylhet.

\section{Materials and Methods:}

This cross-sectional study was conducted in the Department of Ophthalmology, Sylhet MAG Osmani Medical College Hospital, Sylhet during the period from 1st January 2015 to 31st December 2016. Ninety (90) patients of non-viral microbial keratitis aged older than 18 years and both sexes were included. Patients with suspected viral keratitis (typical dendritic ulcers with decreased corneal sensations), shield corneal ulcer of vernal catarrh, neurotrophic corneal ulcers (painless ulcers without infiltrates and minimal conjunctival congestion) and systemic disease associated with keratitis were excluded from the study. All the patients were assessed by history, physical examination and investigations. Non-viral microbial keratitis was defined as loss of corneal epithelium with underlying stromal infiltrate associated with signs of inflammation with or without hypopyon. ${ }^{11}$ Ocular examination of visual acuity, corneal sensation and slit lamp examination was done to detect any other eye diseases. The best corrected visual acuity in Snellen format (BCVA) at the time of admission, ulcer size in $\mathrm{mm}$ along greatest dimension and hypopyon (vertical height in $\mathrm{mm}$ at 6 o'clock) using slit lamp were also documented.

Pattern of organisms on culture: A sterile cotton swab soaked with sterile normal saline was used to collect specimens from base and margin of the ulcer by rubbing before instillation of local anesthetic. It was inoculated on to Blood agar and MacConkey's agar and incubated at $37^{\circ} \mathrm{C}$ for 24 hours in the Department of Microbiology, Sylhet MAG Osmani Medical College, Sylhet. Bacteria grown in colonies were identified presumptively on the Blood agar and MacConkey's agar by following colony characteristics against each of the organism. The isolates were further identified using standard identification protocol such as Gram's staining, motility test and biochemical tests. Catalase test, coagulase test and mannitol fermentation tests were done for the identification of $S$. aureus and S. epidermidis. Members of enterobacteriaceae such as E. coli, Klebsiella and Pseudomonas were identified by their characteristics of sugar fermentation, indole production and citrate utilization.

Fungal microscopy and culture: Three corneal scrapings were taken from leading edge and floor of ulcer using Bard-Parker blade (No.15) after instillation of $0.4 \%$ oxybuprocain without preservative. First scraping was used for $10 \%$ potassium hydroxide $(\mathrm{KOH})$ wet mount. Fungus was cultured on Sabouraud's Dextrose Agar (SDA) media from second scraping material and last scraping was used for gram staining. Inoculated SDA media was incubated at $25^{\circ} \mathrm{C}$ and was observed daily for first 7 days and on alternate days for the next 7 days for observing slow growing fungi. Identification of fungal growth was done by its macroscopic and microscopic features. This procedure was done in the department of microbiology under supervision of microbiologist. Identification of fungi: The fungi grown in primary plates and subcultures were identified on the basis of their gross colonial characteristics and microscopic findings.

Microscopic examination of colony: Scotch tape mount was applied for microscopic study of the colony character of isolated fungi.

Scotch tape mount: For making this mount, a clean glass slide was taken and lactophenol cotton blue stain was placed in the slide, then the sticky surface of the scotch tape was touched to the surface of the fungus out growth. The sticky surface of the tape was then pressed down to a slide and examined under microscope using 10x and 40x objectives.

Gross characteristics of colony: Colonial characteristics such as colour of surface and reverse side (i.e. white, cream, brown, buff, pink, brick-red, yellow etc.), topography (contours, margin, elevation, folding etc.) and texture (granular, powdery, velvety, waxy etc.) were observed and recorded.

Intervention: All patients were treated conservatively. (1) For bacterial keratitis with ciprofloxacin orally, moxifloxacin eye drop and atropine eye drop; and (2) For fungal kerartitis fluconazole orally, natamycin eye drop and atropine drop.

Statistical Analysis: Data were processed manually and analyzed using SPSS (Statistical Package for Social Sciences) Version 21.0. A probability value of $p<0.05$ was considered statistically significant.

Ethical Consideration: Informed consent was taken after discussing purpose of the study in detailed. An approval of the study protocol was obtained from the ethical committee of Sylhet MAG Osmani Medical College, Sylhet before the commencement of the study.

\section{Results:}

The age of the patients ranged from 18 years to 75 years with the mean age of $46.71 \pm 16.52$ years with male predominance (1.2:1). Farmer (34.4\%) and house wife $(30.0 \%)$ were the most frequent occupations, while primary education $(30.0 \%)$ and illiterate $(25.6 \%)$ were the level of education in most cases (Table-I).

Table-I: Socio-demographic characteristics of the patients $(\mathrm{n}=90)$.

\begin{tabular}{lcc}
\hline Variables & Frequency & Percentage \\
\hline Age & 13 & \\
15-24 years & 14 & 14.4 \\
25-34 years & 12 & 15.6 \\
35-44 years & 21 & 13.3 \\
45-54 years & 13 & 23.3 \\
55-64 years & 17 & 14.4 \\
65-75 years & 18.9 \\
\hline
\end{tabular}




\begin{tabular}{lcc}
\hline Variables & Frequency & Percentage \\
\hline Sex & 49 & 54.4 \\
Male & 41 & 45.6 \\
Female & & \\
Occupation & 31 & 34.4 \\
Farmer & 13 & 14.4 \\
Manual workers & 11 & 12.2 \\
Student & 27 & 30.0 \\
House wife & 8 & 8.9 \\
Others & & \\
Educational status & 23 & 25.6 \\
Illiterate & 27 & 30.0 \\
Primary & 18 & 20.0 \\
Secondary & 10 & 11.1 \\
SSC & 12 & 13.3 \\
HSC or above & & \\
Residence & 52 & 57.8 \\
Rural & 38 & 42.2 \\
Urban & &
\end{tabular}

Clinical features were watering and redness of eye $(100.0 \%)$, pain or burning sensation $(75.6 \%)$ and dimness of vision (100.0\%); and the signs were blepharospasm $(93.3 \%)$, cilliary congestion $(100.0 \%)$, corneal opacity $(100.0 \%)$ and corneal vascularization (16.7\%) (Table-II).

Table-II: Showing distribution of patients according to clinical presentation $(n=90)$.

\begin{tabular}{lcc}
\hline Clinical Presentation & Frequency & Percentage \\
\hline Symptoms & 90 & 100.0 \\
Watering and Redness & 68 & 75.6 \\
Pain or burning sensation & 90 & 100.0 \\
Dimness of vision & & \\
Signs & 84 & 93.3 \\
Blepharospasm & 90 & 100.0 \\
Ciliary congestion & 90 & 100.0 \\
Corneal opacity & 15 & 16.7 \\
Corneal vascularization &
\end{tabular}

Common predisposing factors were trauma (66.7\%) and chronic dacryocystitis (25.6\%) (Table-III).

Table-III: Showing distribution of patients according to predisposing factors of non-viral microbial keratitis $(n=90)$.

\begin{tabular}{lcc}
\hline Predisposing Factors & Frequency & Percentage \\
\hline Trauma & 60 & 66.7 \\
Paddy & 42 & 46.7 \\
Leaf & 10 & 11.1 \\
Soil & 6 & 6.7 \\
Blunt trauma & 2 & 2.2 \\
Chronic dacryocystitis & 23 & 25.6 \\
Entropion & 5 & 5.6 \\
Exposure keratitis & 2 & 2.2 \\
\hline Total & 90 & 100.0
\end{tabular}

Visual acuity at presentation was $6 / 12$ in $10(11.1 \%)$ patients, 6/18 in $12(13.3 \%)$ patients, 6/24 in $17(18.9 \%)$ patients, $6 / 36$ in 31 (34.4\%) patients, $6 / 60$ in $7(7.8 \%)$ patients and perception of light in $13(14.4 \%)$ patients.

Culture was found positive in 77 (85.6\%) cases with pure fungal growth in $47(52.2 \%)$ cases, pure bacterial growth in $7(7.8 \%)$ cases and mixed growth (both fungus and bacteria) in $23(25.6 \%)$ cases. Therefore fungal growth was in 70 (77.8\%) cases and bacterial growth in 30 (33.3\%) cases. Significantly higher frequency of fungal growth was isolated than that of bacterial growth $\left(\chi^{2}=16.000 ; p<0.01\right)$. Staphylococcus epidermidis $(11.1 \%)$ and Staphylococcus aureus (3.3\%) were gram positive organisms; while Pseudomonas aeruginosa (12.2\%), Klebsiella species (3.3\%) and Escherichia coli $(3.3 \%)$ were gram negative organisms (Table-IV). Aspergillus species (55.0\%) was the commonest fungus of which Aspergillus nigar (22.2\%), Aspergillus Alavus (17.8\%), Aspergillus terreus (7.8\%) and Aspergillus fumigatus (7.8\%). Others were Penicillium species (5.6\%), Fusarium species (6.7\%), Mucor (7.8\%) and Rhizopus (2.2\%) (Table-IV).

Table-IV: Showing isolation of organism from patients with non-viral microbial keratitis $(n=90)$.

\begin{tabular}{lcc}
\hline Organism & Frequency & Percentage \\
\hline Bacteria & & \\
$\quad$ Staphylococcus epidermidis & 10 & 11.1 \\
Staphylococcus aureus & 3 & 3.3 \\
Klebsiella species & 3 & 3.3 \\
Pseudomonas aeruginosa & 11 & 12.2 \\
Escherichia coli & 3 & 3.3 \\
Fungus & & \\
Aspergillus nigar & 20 & 22.2 \\
Aspergillus terreus & 7 & 7.8 \\
Aspergillus flavus & 16 & 17.8 \\
Aspergillus fumigatus & 7 & 7.8 \\
Penicillium species & 5 & 5.6 \\
Fusarium species & 6 & 6.7 \\
Mucor & 7 & 7.8 \\
Rhizopus & 2 & 2.2 \\
\hline
\end{tabular}

Discussion:

Regarding the age distribution, the age of the patients ranged from 18 years to 75 years with the mean age of 46.71 \pm 16.52 years. These findings were consistent with the study done by many other workers ${ }^{6,12-14}$. In the present study, males were predominant with a ratio of male to female was 1.2:1. It was matched with other studies done in different countries ${ }^{6,15,16}$. Regarding occupation, this study revealed that most of the patients were farmer $(34.4 \%)$ and house wife $(30.0 \%)$. This finding was comparable with the studies done in other countries ${ }^{12-14,16}$. This study showed that primary $(30.0 \%)$ and illiterate $(25.6 \%)$ were the frequent level of education. Payal et al. ${ }^{17}$ reported $79 \%$ patients were literate and $21 \%$ were illiterate in their study in Western India. 
In this study, majority of the patients $(57.8 \%)$ were from rural area and the rest were (42.2\%) from urban area. This finding was comparable with other studies ${ }^{6,13,14,16}$. In this study the symptoms at presentation were watering and redness of eye $(100.0 \%)$, pain or burning sensation $(75.6 \%)$ and dimness of vision (100.0\%). The signs at presentation were cilliary congestion $(100.0 \%)$, corneal opacity (100.0\%), blepharospasm (93.3\%) and corneal vascularization (16.7\%). The Hong Kong Microbial Keratitis Study Group,${ }^{18}$ reported that the major presenting symptoms of microbial keratitis were red eye $(56 \%)$, blurring of vision $(50 \%)$, foreign body sensation (32\%), eye discharge $(22 \%)$, photophobia $(14 \%)$ and pain $(72 \%)$ cases. Rubab et al. ${ }^{19}$ found that the common clinical findings included mild conjunctivitis $(38.7 \%)$, purulent conjunctivitis (14.7\%), corneal ulcer (24\%), corneal abscess (11.3), hypopyon $(9.3 \%)$, descemetocele $(3.3 \%)$ and corneal perforation $(2.7 \%)$ cases. In this study the visual acuity at presentation was $6 / 12$ in $10(11.1 \%)$ patients, $6 / 18$ in $12(13.3 \%)$ patients, 6/24 in $17(18.9 \%)$ patients, 6/36 in 31 (34.4\%) patients, $6 / 60$ in $7(7.8 \%)$ patients and perception of light in $13(14.4 \%)$ patients. Rubab et al al. ${ }^{19}$ found that $74.3 \%$ affected eyes with keratitis were suffering from severe visual impaired or blindness $(<6 / 60$ to no perception of light). Hussain et al. ${ }^{11}$ checked visual acuity in 214 patients (93.8\%), and the rest being young children and found that 20 patients $(9.3 \%)$ had good vision $(\geq 6 / 18), 23(10.7 \%)$ had moderate vision $(\leq 6 / 24$ to $\geq 6 / 60)$ and $171(79.9 \%)$ had poor vision $(<6 / 60)$ at presentation. The most common predisposing factor was trauma $(66.7 \%)$ and the trauma are due to paddy $(46.7 \%)$, leaf $(11.1 \%)$ soil $(6.7 \%)$ and blunt trauma $(2.2 \%)$, other predisposing factors were chronic dacryocystitis $(25.6 \%)$, entropion $(5.6 \%)$ and exposure keratitis $(2.2 \%)$. The findings coincided well with other studies $^{13,20}$. Trauma was found to be the most common risk factor reported in the developing world ${ }^{21-23}$. In the developed world, the use of contact lens is the commonest risk factor for microbial keratitis ${ }^{24}$. The reason might be that the use of contact lens has not gained much popularity in Bangladesh. This study showed that culture was positive in $77(85.6 \%)$ cases. Fungal growth was isolated in $70(77.8 \%)$ cases and bacterial growth in $30(33.3 \%)$ cases. Significantly higher frequency of fungal growth was isolated than that of bacterial growth $(p<0.01)$. Pure fungal growth was isolated in 47 $(52.2 \%)$ cases, pure bacterial growth in $7(7.8 \%)$ cases, mixed microbial growth (both fungus and bacteria) in 23 (25.6\%) cases and no growth was observed in $13(14.4 \%)$ cases. Similar findings were reported in a study in Bangladesh, ${ }^{6}$ and several studies in India, ${ }^{13,15}$ But Dunlop et al. ${ }^{25}$ isolated $53.5 \%$ bacterial and $35.9 \%$ fungal agents in a study conducted in Chittagong Eye Infirmary, Bangladesh. Akter et al. showed $42.86 \%$ fungal growth, $25 \%$ bacterial growth and $16.07 \%$ mixed microbial growth (both bacteria and fungi) in a study in Rajshahi Medical College Hospital ${ }^{16}$. In this study Aspergillus species (55.0\%) was the commonest fungus of which Aspergillus nigar (22.2\%), Aspergillus
Alavus (17.8\%), Aspergillus terreus (7.8\%) and Aspergillus fumigatus (7.8\%). Others were Penicillium species (5.6\%), Fusarium species (6.7\%), Mucor (7.8\%) and Rhizopus $(2.2 \%)$. The fungal species detected in the present study was equally comparable with that of others ${ }^{13,14}$. Aspergillus species was the most predominant fungal pathogen in Bangladesh, Eastern India, Egypt and Uttarakhand, India ${ }^{6,13,14,16}$. Gram positive bacterial Isolates in the present study were Staphylococcus epidermidis (11.1\%) and Staphylococcus aureus (3.3\%); while gram negative organisms were Pseudomonas aeruginosa (12.2\%), Klebsiella species (3.3\%) and Escherichia coli (3.3\%). Staphylococcus epidermidis was isolated in $21.9 \%$ and $20 \%$ cases in Iran and Oman respectively ${ }^{12,26}$. Pseudomonas species was the most common representing bacterial isolates were seen in other studies in Bangladesh, Iran, Thailand, Oman and Hong Kong ${ }^{12,15,25,26}$. But Tewari et al. ${ }^{27}$ found 32.7\% Staphylococcus aureus, 6.8\% Klebsiella species and 5.1\% Escherichia coli in Ahmedabad, India. These might be due to variation in the principle causative microbial agents of infective corneal ulcer in different countries.

\section{Conclusion:}

It may be concluded that fungi are more frequent cause of non-viral keratitis. Watering, redness, pain or burning sensation, corneal opacity and dimness of vision are clinical profiles; and the common predisposing factors are trauma and chronic dacryocystitis. Ophthalmologist should keep in mind that fungus may be the cause of non-viral microbial keratitis. Avoid ocular trauma to prevent non-viral microbial keratitis including bacterial and fungal infection. However further large scale multicentre study is warranted.

Conflict of Interest: None.

\section{Acknowledgement:}

We are grateful to the patients who gave their consent for taking part of this study. The authors also thank to Director, Sylhet MAG Osmani Medical College, Sylhet for giving permission to collect data.

\section{References:}

1. Sihota R, Tandon R. Diseases of the cornea. In: Parsons's Diseases of the Eye. 21st ed. New Delhi: Elsevier publishers; 2011: 188-207.

2. Dandona L, Dandona R, Srinivas M. Giridhar P, Vilas K, Prasad MN, et al. Blindness in the Indian state of Andhra Pradesh. Invest Ophthalmol Vis Sci. 2001;42:908-16.

3. Dineen BP, Bourne RRA, Ali SM, Huq DMN, Johnson GJ. Prevalence and causes of blindness and visual impairment in Bangladeshi adults-results of the National Blindness and Low Vision Survey of Bangladesh. Br J Ophthalmol. $2003 ; 87: 820-8$

https://doi.org/10.1136/bjo.87.7.820

PMid:12812875 PMCid:PMC1771736

4. Dineen B, Bourne RR, Jadoon Z, Shah SP, Khan MA, 
Foster A, et al. Pakistan National Eye Survey Study Group. Causes of blindness and visual impairment in Pakistan. The Pakistan national blindness and visual impairment survey. Br J Ophthalmol. 2007;91:1005-10.

https://doi.org/10.1136/bjo.2006.108035

PMid:17229806 PMCid:PMC1954803

5. Khan MU, Haque MR. Prevalence and Causes of Blindness in Rural Bangladesh. Ind J Med Res. 1985;82:257-62. 6. Ahmed S, Ghosh A, Hassan SA, Tarafder S, Miah MRA. Predisposing Factors and Aetiologic Diagnosis of Infectious Corneal Ulcer. Bangladesh J Med Microbiol. 2010;04 (01):28-31.

https://doi.org/10.3329/bjmm.v4i1.8466

7. Narsani AK, Jatoi SM, Khanzada MA, Lohana MK. Etiological Diagnosis of Microbial Keratitis. J Coll Phys Surg Pak. 2010;20(9):604-7.

8. Narsani AK, Nangdev PR, Surhio SA, Kumar M, Jatoi SM. Demographic Pattern, Risk Factors, Clinical and Microbiological Characteristics of Fungal Keratitis. JLUMHS. 2012;11(01):42-6.

9. Gebremariam TT, Alemu TA, Daba KT. Bacteriology and Risk Factors of Bacterial Keratitis in Ethiopia. Health Sci J. 2015; 9(5):6.

10. Narsani AK, Jatoi SM, Lohana MK, Dabir SA, Gul S, Khanzada MA. Hospital-base epidemiology, risk factors and microbiological diagnosis of bacterial corneal ulcer. Int J Ophthalmol. 2009;2(4):362-6.

11. Hussain I, Khan BS, Soni M, Iqbal M, Habibullah. Non-Viral Microbial Keratitis: Etiology, Clinical Features and Visual Outcome. J Coll Phys Surg Pak. 2012;22(3):151-4.

12. Shoja MR, Manaviat M. Epidemiology and outcome of corneal ulcers in Yazd Shahid Sadoughi Hospital. Acta Med Iranica. 2004;42:136-41.

13. Basak SK, Basak S, Mohanto A, Bhowmick A. Epidemiological and microbiological diagnosis of suppurative keratitis in Gangetic West Bengal, Eastern India. Ind $\mathbf{J}$ Ophthalmol. 2005;53:17-22.

https://doi.org/10.4103/0301-4738.15280

PMid:15829742

14. Chhangte L, Pandey S, Umesh. Epidemiological and microbiological profile of infectious corneal ulcers in tertiary care centre, Kumaon Region, Uttarakhand. Int J Sci Res Pub. 2015;05:1-5.

15. Tananuvat N, Sienglew S, Ausayakhun S. Microbial keratitis leading to admission at Maharaj Nakorn Chiang Mai Hospital. Chiang Mai Med Bull. 2004;43:93-103.

16. Akter L, Salam MA, Hasan B, Begum N, Ahmed I. Etiological agents of suppurative corneal ulcer: Study of 56 cases. Bangladesh J Med Microbiol 2009;03(01):33-6.

https://doi.org/10.3329/bjmm.v3i2.5325

17. Payal R, Purav P, Sima B. Epidemiology, predisposing factors and etiology of fungal keratitis in a tertiary eye care hospital in Western India. National J Med Research. 2014;04:345-8.
18. Hong Kong Microbial Keratitis Study Group (Prince of Wales Hospital and Hong Kong Eye Hospital). Etiological agents and risk factors of microbial keratitis in Hong Kong: a preliminary report on the first 50 cases. Hong Kong Journal of Ophthalmology. 1997;(3):99-103.

19. Rubab S, Awan H, Khan WA. Comparison of indigenous microbial flora of the eye to that found in conjunctival and corneal infections in a hospital based study. Pak J Ophthalmol. 2006;22:97-110.

20. Jeevitha M, Manavalan S, Mishra P, Sridevi S. Clinical study of various factors in etiopathogenesis and management of microbial keratitis. Int $\mathrm{J}$ Modn Res Revs. 2015;3(10):861-4.

21. Jatoi SM, Qureshi MA, Laghari NA, Dahar MY. Etiologic diagnosis of infective ulcerative keratitis. Pak J Ophthalmol. 2002;18:40-3.

22. Vajpayee RB, Dada T, Saxena R, Vajpayee M, Taylor HR, Venkatesh P, et al. Study of the first Contact management profile of cases of infective keratitis: a hospital based study. Cornea. 2000;19:52-6.

https://doi.org/10.1097/00003226-200001000-00011

PMid:10632009

23. Gopinathan U, Sharma S, Garg P, Rao GN. Review of epidemiological features, microbiological diagnosis and treatment outcome of microbial keratitis: experience of over a decade. Indian J Ophthalmol. 2009;57:273-9.

https://doi.org/10.4103/0301-4738.53051

PMid:19574694 PMCid:PMC2712695

24. Boureier T, Thomas F, Borderie V, Chaumeil C, Laroche L. Bacterial keratitis: Predisposing factors, clinical and micro-biological review of 300 cases. Br J Ophthalmol 2003;87:834-8.

https://doi.org/10.1136/bjo.87.7.834

PMid:12812878 PMCid:PMC1771775

25. Dunlop AA, Wright ED, Howlader SA, Nazrul I, Hussain R, Mcclellan K, et al. Suppurative Corneal Ulceration in Bangladesh: A Study of 142 Cases Examining The Microbiological Diagnosis, Clinical And Epidemiological Features of Bacterial And Fungal Keratitis. Aust N A J Ophthalmol 1994;22(2):105-10.

https://doi.org/10.1111/j.1442-9071.1994.tb00775.x

PMid:7917262

26. Keshav BR, Zacheria G, Ideculla T, Bhat V, Joseph M. Epidemiological characteristics of corneal ulcers in south Sharqiya region. Oman Med J. 2008;23:34-9.

27. Tewari A, Sood N, Vegad MM, Mehta DC. Epidemiological and microbiological profile of infective keratitis in Ahmedabad. Ind J Ophthalmol. 2012;60:268-72.

https://doi.org/10.4103/0301-4738.98702

PMid:22824594 PMCid:PMC3442460 